Revista Destaques Acadêmicos, Lajeado, v. 8, n. 4, 2016. ISSN 2176-3070 DOI: http://dx.doi.org/10.22410/issn.2176-3070.v8i4a2016.1238 www.univates.br/revistas

\title{
A AÇÃO ENZIMÁTICA COMO FOCO DO SURGIMENTO DO ALTO ÍNDICE DE CASEINOMACROPEPTÍDEO NO LEITE UHT
}

\author{
Robson Wegner Cavalheiro' ${ }^{1}$, Francisco Abrahão ${ }^{2}$, Wolmir Jose Bockel ${ }^{3}$
}

\begin{abstract}
Resumo: A busca incondicional pela qualidade alimentícia tem projetado vários estudos ligados à qualidade e controle de fraudes no leite. $\mathrm{O}$ trabalho proposto buscou avaliar a ação das enzimas proteases, produzidas por microrganismos psicrotróficos, no alto índice de caseinomacropeptídeo (CMP) no leite UHT ao longo do tempo de estocagem e também comparando com amostras fraudadas propositalmente com soro de queijo. Foram analisadas amostras de um lote de leite UHT, sua respectiva matéria-prima, e após o processo de pasteurização e padronização, e o produto pronto ao longo de seu shelf life. Neste estudo foi utilizado a Cromatografia Líquida de Alta Eficiência (CLAE) para a determinação do CMP, este é um método internacionalmente reconhecido e oficializado no Brasil pela Instrução Normativa IN n 68 de 2006 do Ministério da Agricultura, Pecuária e Abastecimento (MAPA). A análise do índice de CMP é avaliada pela porção da molécula de proteína k-caseína solúvel no soro, como indicador da ocorrência da fraude da adição de soro de queijo. No entanto, a ação de proteases pode interferir neste teste levando a resultados falso-positivos, situação que passou a ter maior importância desde a implementação da IN n ${ }^{\circ} 51$ de 2002 e, posteriormente, da IN $\mathrm{n}^{\circ} 62$ de 2011 que exige que o leite deve ser refrigerado.
\end{abstract}

Palavras-chave: Caseinomacropeptídeo. Leite UHT. Soro de queijo.

\section{INTRODUÇÃO}

O leite é um importante produto de origem animal, e uma das principais fontes de proteínas na alimentação humana. Segundo a Instrução Normativa ${ }^{\circ}$ 51 "é o produto oriundo da ordenha completa, ininterrupta, em condições de higiene, de vacas sadias, bem alimentadas e descansadas" (BRASIL, 2002). É considerado um dos alimentos mais completos para a dieta humana devido a

1 Centro Universitário UNIVATES.

2 Centro Universitário UNIVATES.

3 Centro Universitário UNIVATES. 
sua composição nutricional. Ele é uma mistura homogênea constituído por uma maior porção de água, onde os demais componentes são gordura, proteínas e carboidratos, substâncias nitrogenadas não proteicas, sais minerais, vitaminas, enzimas e pigmentos (TRONCO, 2008).

Tendo em vista esta grande importância do leite como alimento, o Ministério da Agricultura, Pecuária e Abastecimento (MAPA), estabelece parâmetros para que o controle deste produto seja feito com qualidade, na busca de um produto próprio para o consumo. Umas das fraudes econômicas mais comuns no leite fluido é a adição de soro proveniente da fabricação do queijo, por ser um subproduto de baixo custo à indústria. Esta adição como qualquer outra fraude é proibida pela legislação, por diminuir o valor nutritivo do alimento. Mas em outros produtos derivados do leite, o soro de queijo é um ingrediente de uso comum. A maior parte do volume do soro, entretanto, não é reaproveitada pela indústria. Na tentativa de não descartar esse subproduto como resíduo, ocorre a reutilização do soro adicionando-o ao leite a ser comercializado. O objetivo maior dessa incorporação no leite é aumentar o seu volume, caracterizando-se, assim, como fraude econômica. Por isso, não existe permissão legal para a sua adição ao leite (BRASIL, 2006).

O soro proveniente da fabricação do queijo é conhecido como um produto de alto valor nutritivo, porém, poucos setores têm feito um correto aproveitamento desta fonte de nutrientes levando a um grande desperdício. O soro fluido apresenta uma composição média de 4,6\% de lactose, 0,5 $\%$ de gordura e $0,8 \%$ de proteínas, principalmente betalactoglobulinas, alfa-lactoalbuminas e imonoglobulinas que são valiosas do ponto de vista nutricional, apresentando vários aminoácidos essenciais. A crescente demanda por alimentos cada vez mais nutritivos, acessíveis e com menor custo de produção, torna o soro uma importante fonte de nutrientes nobres, passíveis de serem recuperados e empregados na elaboração de uma grande quantidade de produtos alimentícios.

A adição de soro ao leite é normalmente detectada pela determinação do caseinomacropeptídeo (CMP), um fragmento hidrofílico da o-caseína, liberado pela ação da quimosina durante a coagulação enzimática do leite que permanece solúvel no soro e que deveria estar ausente no leite. Porém, a presença de CMP no leite cru refrigerado pode ocorrer em função do sistema proteolítico do próprio leite. Quanto maior o tempo de armazenamento do leite resfriado, maiores as chances de multiplicação microbiana, em especial dos microrganismos psicrotróficos. Geralmente, esta microbiota se torna predominante no leite resfriado após dois ou três dias (LORENZETTI, 2006).

Uma importante característica dos psicrotróficos comumente encontrados no leite e produtos derivados é a sua capacidade de síntese de enzimas extracelulares que degradam os componentes do leite. Por isso, as proteases produzidas por bactérias psicrotróficas agem sobre a caseína de forma semelhante a quimosina, liberando CMP (LORENZETTI, 2006). Por 
outro lado, a atividade proteolítica das enzimas termorresistentes, liberadas por bactérias psicotróficas, em leite cru e as que permanecem ativas em leite UHT, podem acarretar na liberação de CMP. Isto devido da capacidade das enzimas proteolíticas de hidrolisar a caseína em locais quimicamente semelhantes aos da hidrólise pela pela quimosina. Os microrganismos psicrotróficos tem a capacidade de crescimento a $7{ }^{\circ} \mathrm{C}$ sendo a causa mais importante de produtos com baixa qualidade. $\mathrm{Na}$ indústria de laticínios, os grandes volumes de leite ficam armazenados à temperatura de refrigeração entre 1 a $6{ }^{\circ} \mathrm{C}$ por longos períodos. Assim as bactérias psicrotróficas encontram condições para seu desenvolvimento (LORENZETTI, 2006).

Os microrganismos psicrotróficos quando presentes no leite refrigerado, principalmente no in natura, interferem na qualidade do produto final. $\mathrm{O}$ leite proveniente de animais sadios, em condições de ordenha adequadas, contém poucos microrganismos. Se produzido de forma adequada de higiene, o leite poderá conter menos de $10 \%$ de psicrotróficos em relação à microbiota total. Mas este produto pode sofrer contaminação posteriormente a sua ordenha a partir do ambiente e do homem, através dos métodos de manejos utilizados, da forma ou tipo de ordenha, assim o grupo microbiano poderá contribuir com mais de $75 \%$ no aumento de microrganismos psicotróficos (TRONCO, 2008). Estas bactérias crescem a uma temperatura de $7^{\circ} \mathrm{C}$ ou menos, independentes de sua temperatura ótima de multiplicação. As bactérias psicrotróficas pertencem a vários gêneros como Pseudomonas, Enterobacter, Flavobacterium, Klebsiella, Aeromonas, Acinetobacter, Alcaligenes, Achromobacter (EMBRAPA, 2003).

Durante a pasteurização, grande parte dos psicrotróficos é destruída, mas este tratamento tem poucos resultados sobre a atividade das enzimas termorresistentes produzidas por estes microrganismos (CUNHA e BRANDÃO, 2000). Mesmo após os microrganismos psicrotróficos serem inativados pelo processo de pasteurização do leite a termorresistência de proteases bacteriana e a atividade residual elevada pode ser detectada após os tratamentos térmicos, uma vez que as enzimas produzidas continuam provocando alterações no produto, mesmo após a pasteurização ou ultra pasteurização (PINTO, CARDOSO, VANETTI, 2004; TRONCO, 2008). Segundo o Regulamento Técnico de Identidade e Qualidade do leite UHT (BRASIL, 1996, item 2.1) "entende-se por leite UHT (Ultra Alta Temperatura, UAT) o leite (integral, parcialmente desnatado ou semidesnatado e desnatado) homogeneizado que foi submetido, durante 2 a 4 segundos, a uma temperatura entre $130^{\circ} \mathrm{C}$ e $150{ }^{\circ} \mathrm{C}$, mediante um processo térmico de fluxo contínuo, imediatamente resfriado a uma temperatura inferior a $32{ }^{\circ} \mathrm{C}$ e envasado sob condições assépticas em embalagens estéreis e hermeticamente fechadas". A ultra pasteurização pelo processo UHT tem como objetivo produzir um produto comercialmente estéril e que mantenha as características nutritivas e organolépticas do produto fresco (TRONCO, 2008), este processo busca a obtenção de um produto microbiologicamente estável 
mediante a destruição dos microrganismos mais termorresistentes, ou seja, as formas esporuladas das bactérias (ORDÓÑEZ, 2005).

Segundo Ordóñez (2005), as enzimas produzidas por pseudomonas apresentam termorresistência ao processo UHT, como consequência permanecem ativas após o tratamento térmico e atacam seus substratos correspondentes. As proteases de pseudomonas dão origem a sabores amargos e geleificações, isto devido ao ataque sobre a $\beta$-caseína e a $\kappa$-caseína, que produzem peptídeos hidrófobos e a desestabilização da micela de caseína.

No Brasil, e também na maior parte do mundo, está tendo uma grande atenção a prática das fraudes no leite. A adição intencional do soro de queijo no leite é uma delas, sendo um subproduto de baixo valor comercial ou quase nulo, é utilizado para mascarar a adição de água no leite, pois possui uma boa quantidade de sólidos totais. Esta fraude, por ter métodos de detecção caros ou muito lentos, é difícil de ser controlada. Os métodos oficiais para a pesquisa de soro em leite referem-se à determinação quantitativa de ácido siálico e a determinação quantitativa de caseinomacropeptídeo por cromatografia líquida de alta eficiência (CLAE) (TRONCO, 2008).

$\mathrm{O}$ método de determinação e quantificação do índice de CMP por cromatografia por exclusão é reconhecido como método oficial pela Instrução Normativa $\mathrm{N}^{\mathrm{O}} 68$ (BRASIL, 2006). O princípio do índice de CMP baseia-se na detecção e quantificação de caseinomacropeptídeo proveniente da ação proteolítica de enzimas, por meio da cromatografia líquida de alta eficiência (CLAE) com separação em coluna de filtração em gel e detecção em ultravioleta (UV). Este resultado deve ser expresso em miligramas de CMP por litro conforme IN 68, o qual não pode ultrapassar o limite de $30 \mathrm{mg} \mathrm{L}^{-1}$ de CMP (BRASIL, 2006). O trabalho proposto buscou avaliar a ação das enzimas proteases, produzidas por microrganismos psicrotróficos, no alto índice de caseinomacropeptídeo (CMP) no leite UHT ao longo do tempo de estocagem e também comparando com amostras fraudadas propositalmente com soro de queijo. Foram analisadas amostras de um deferido lote de leite UHT, sua respectiva matéria-prima, e após o processo de pasteurização e padronização, e o produto pronto ao longo de seu shelf-life.

\section{MATERIAL E MÉTODOS}

Verificou-se a origem do leite processado pela empresa de laticínios, sendo esta matéria-prima proveniente de produtores rurais cadastrados junto à empresa, onde estes recebem assistência técnica especializada para o cuidado do rebanho.

Coletou-se, em triplicata, amostras de leite in natura do silo isotérmico de estocagem $\left(6{ }^{\circ} \mathrm{C}\right)$, amostras de leite pasteurizado $\left(6{ }^{\circ} \mathrm{C}\right)$ e vinte e quatro amostras do leite envasado no processo UHT. Tanto o leite pasteurizado quanto 
o UHT são de origem do mesmo lote do leite in natura, mas já passando pelos processos térmicos.

As amostras de leite UHT foram submetidas à estocagem em diferentes temperaturas. Doze amostras foram incubadas a $35{ }^{\circ} \mathrm{C}$ pelo período de 30 dias, este procedimento simula parte da vida de prateleira do leite UHT, assim, há um aceleramento no processo de proteólise natural do leite, forçando a ação enzimática. $\mathrm{O}$ restante das amostras foi estocado pelos mesmos 30 dias, em temperatura entre 20 e $24^{\circ} \mathrm{C}$.

Realizou-se análise de índice de CMP no leite in natura logo em seu recebimento e após sua pasteurização, sendo também realizado análises durante sua estocagem em silo isotérmico. Para o leite UHT, foram realizadas análises logo após o envase e de cinco em cinco dias de estocagem. A Instrução Normativa (IN) $\mathrm{n}^{\circ} 68$ de 2006 do Ministério da Agricultura, Pecuária e Abastecimento oficializa os métodos analíticos oficiais físico-químicos para Controle de Leite e Produtos Lácteos, dentre os quais está estabelecido o método de detecção e quantificação do índice de CMP para determinação da adulteração do leite por adição do soro de queijo (BRASIL, 2006).

O método utilizado para separação e quantificação do CMP foi a cromatografia líquida de alta eficiência - CLAE com separação em coluna de filtração em gel e detecção em ultravioleta (UV), internacionalmente aceita para a quantificação do caseinomacropeptídeo - CMP, devido à sua precisão na detecção da presença fraudulenta de soro no leite.

A curva analítica foi preparada com no mínimo 5 soluções padrão de CMP que contemple no mínimo, um ponto abaixo de $30 \mathrm{mg} \mathrm{L}^{-1}$ e um ponto acima de $75 \mathrm{mg} \mathrm{L}^{-1} \mathrm{em}$ matriz branca de leite fluido integral, isto é, utilizou-se leite cru recém ordenhado de precedência conhecida, adicionando a este 10,0; 30,0; 50,0; 75,0 e 100,0 $\mathrm{mg} \mathrm{L}^{-1}$ de padrão de CMP, além de uma amostra para o branco (0 $\mathrm{mg} \mathrm{L}^{-1}$ de CMP). Uma quantidade de 5,0 $\mathrm{mL}$ de ácido tricloroacético ( $24 \%$ ) foi adicionada lentamente a $10 \mathrm{~mL}$ de cada solução padrão, e deixada em repouso durante 60 minutos à temperatura ambiente, seguidos por filtração em papel qualitativo, eliminando as primeiras gotas. O ácido tricloroacético é um agente precipitante, que é utilizado para separar peptídeos de proteínas, por diferença de solubilidade (BRASIL, 2006).

Para o tratamento das amostras analíticas, foi retirada uma alíquota de 10 $\mathrm{mL}$ e adicionados $5 \mathrm{~mL}$ de ácido tricloroacético a $24 \%$ gota a gota e sob agitação constante, deixando em repouso por 60 minutos à temperatura ambiente, sendo após filtrada em papel qualitativo descartando as primeiras gotas do filtrado. No caso de amostras turvas, deve-se filtrar em unidade filtrante com $0,45 \mu \mathrm{m}$. Após o tratamento das amostras, foi injetado o volume de $30 \mu \mathrm{L}$ de cada amostra tratada no sistema cromatográfico em uma corrida de $15 \mathrm{~min}$, com uma coluna Zorbax $250 \mathrm{GF} 9,4 \mathrm{~mm} \times 250 \mathrm{~mm}$, com um fluxo isocrático da fase móvel (com um pH de 6,0 em solução tampão de fosfato) de 1,0 mL $\mathrm{min}^{-1}$ e detector UV ajustado a $205 \mathrm{~nm}$. A fase estacionária foi composta por 
partículas de sílica esférica com diâmetro de 4,0 a 4,5 $\mu \mathrm{m}$, superfície modificada estabilizada com zircônio, diâmetro de poro $150 \AA$, área superficial de $140 \mathrm{~m}^{2}$ $\mathrm{g}^{-1}$. Os resultados obtidos de índice CMP foram quantificados por análise de altura de pico comparada com a altura do pico de padrões e tempo de retenção (BRASIL, 2006).

O limite de detecção foi calculado em 3,33 vezes o desvio padrão do branco dividido pelo coeficiente angular. O limite de quantificação foi obtido com 10 vezes o valor do desvio padrão do branco, e dividindo pelo coeficiente angular.

\section{RESULTADOS E DISCUSSÃO}

A presente pesquisa foi desenvolvida com o leite processado por uma indústria de laticínios da região sul do Brasil. Na curva analítica obteve-se um coeficiente de correlação linear de 0,998, para então realizar as análises do leite in natura, leite pasteurizado e UHT. Este último com relação ao tempo de estocagem e a temperaturas de 20 a $24{ }^{\circ} \mathrm{C}$ e $35{ }^{\circ} \mathrm{C}$. O limite de detecção e de quantificação foram, respectivamente, de 4,99 e 14,96 $\mathrm{mg} \mathrm{L}^{-1}$.

As análises da matéria-prima, ou seja, leite in natura, apresentaram um baixo índice em CMP, no valor de 10,27 $\pm 0,03 \mathrm{mg} \mathrm{L}^{-1}$. Já o leite pasteurizado e estocado a $6{ }^{\circ} \mathrm{C}$, no valor de 10,91 $\pm 0,05 \mathrm{mg} \mathrm{L}^{-1}$. Constatou-se que as amostras em que foram realizadas análises estão isentas de fraudes, isto é, o índice de CMP do leite in natura, pasteurizado e UHT com um dia de estocagem, em torno de $11,03 \pm 0,02 \mathrm{mg} \mathrm{L}^{-1}$ e em dez dias, $17,41 \pm 0,03 \mathrm{mg} \mathrm{L}^{-1}$, estes valores estão abaixo do limite estabelecido de até $30 \mathrm{mg} \mathrm{L}^{-1}$ (BRASIL, 2006).

A contaminação do leite por microrganismos psicrotróficos está diretamente relacionada com as práticas de manejo utilizado nos animais, do tipo de ordenha e da higienização do animal, isso justificaria a presença de bactérias psicrotróficas no leite in natura (TRONCO, 2008). Por sua vez, Ordóñez (2005) salienta ainda que, o leite refrigerado na propriedade, o transporte em tanques isotérmicos e suas estocagens nos postos de refrigeração e na indústria, propiciam a proliferação de bactérias psicrotróficas. De acordo com a Instrução Normativa $\mathrm{n}^{\circ} 62$ (BRASIL, 2011), o leite pode ser recebido pela indústria com no máximo $10{ }^{\circ} \mathrm{C}$ de temperatura, quando recebido de produtor e $7^{\circ} \mathrm{C}$ quando de origem de postos de resfriamento. Porém, estas temperaturas são ótimas para o crescimento destas bactérias.

Foram realizadas análises em leite com adição de 0 a $20 \%$ em soro e analisado o índice de CMP, respectivamente. Os resultados são apresentados na Tabela 1. Com relação ao percentual de soro adicionado, os valores de CMP aumentam numa taxa de 14 vezes, aproximadamente, e de forma linear $\left(R^{2}=\right.$ $0,998)$. 
Tabela 1 - Concentração de CMP (mg L-1) em leite após adição de 0 a 20 \% em soro

\begin{tabular}{cccccc}
\hline Percentual de soro adicionado (\%) & 0 & 5 & 10 & 15 & 20 \\
\hline Índice de CMP $\left(\mathrm{mg} \mathrm{L}^{-1}\right)$ & 11,61 & 68,60 & 144,75 & 217,84 & 291,42 \\
\hline
\end{tabular}

Fonte: os autores.

Mesmo com a ultra pasteurização pode ocorrer o aumento do índice de CMP e com esta possibilidade realizou-se uma avaliação com relação ao tempo de estocagem e em temperaturas próximas às do leite embalado e estocado no supermercado. Foi acompanhado o índice de CMP num respectivo lote de leite UHT em diferentes temperaturas de estocagem durante aproximadamente 30 dias. Os resultados dos ensaios foram obtidos em triplicata e expressos na Tabela 2.

Tabela 2 - Média do índice de CMP (mg L ${ }^{-1}$ ) do leite UHT do mesmo lote, armazenado a temperaturas de 20 a $24{ }^{\circ} \mathrm{C}$ e $35^{\circ} \mathrm{C}$

\begin{tabular}{|c|c|c|}
\hline \multirow{2}{*}{$\begin{array}{l}\text { Armazenamento } \\
\text { (Dias) }\end{array}$} & \multicolumn{2}{|c|}{$\begin{array}{l}\text { Média em CMP no leite UHT }\left(\mathrm{mg} \mathrm{L}^{-1}\right) \text { de acordo com a } \\
\text { temperatura }\end{array}$} \\
\hline & 20 a $24^{\circ} \mathrm{C}$ & $35^{\circ} \mathrm{C}$ \\
\hline 1 & $11,60 \pm 0,24$ & $14,56 \pm 0,02$ \\
\hline 2 & $13,94 \pm 0,55$ & $31,00 \pm 0,06$ \\
\hline 5 & $32,76 \pm 0,53$ & $51,52 \pm 0,20$ \\
\hline 10 & $39,48 \pm 0,44$ & $66,40 \pm 0,05$ \\
\hline 15 & $65,09 \pm 0,20$ & $106,43 \pm 0,19$ \\
\hline 20 & $68,15 \pm 0,19$ & $119,73 \pm 0,41$ \\
\hline 25 & $71,41 \pm 1,05$ & $221,78 \pm 0,89$ \\
\hline 30 & $77,89 \pm 0,48$ & $320,79 \pm 0,29$ \\
\hline
\end{tabular}

Fonte: os autores.

Observou-se que o leite UHT estocado sob condição de maior temperatura $\left(35^{\circ} \mathrm{C}\right)$, característica de depósitos na estação de verão, apresentou um aumento expressivo no índice de CMP, podendo ser comparado aos valores do índice referentes ao leite que teve soro adicionado propositalmente. Em 20 dias de estocagem a temperaturas médias de $22{ }^{\circ} \mathrm{C}$ e $35^{\circ} \mathrm{C}$, o índice de CMP atingiu valores comparados ao leite com soro adicionado em 4,4 e 8,1 $\%$, respectivamente e em 30 dias, estes valores aumentaram para 5,1 e 22,3\%, respectivamente. Estes valores comparativos foram obtidos da função linear gerada com os dados da Tabela 1. 
Avaliando-se o comportamento do índice de CMP no leite UHT, ao longo de sua estocagem, constatou-se um aumento gradativo neste índice, conforme a Figura 1.

Figura 1 - Índice de CMP nas amostras de leite UHT armazenados até 30 dias nas temperaturas de 20 a 24 e $35^{\circ} \mathrm{C}$

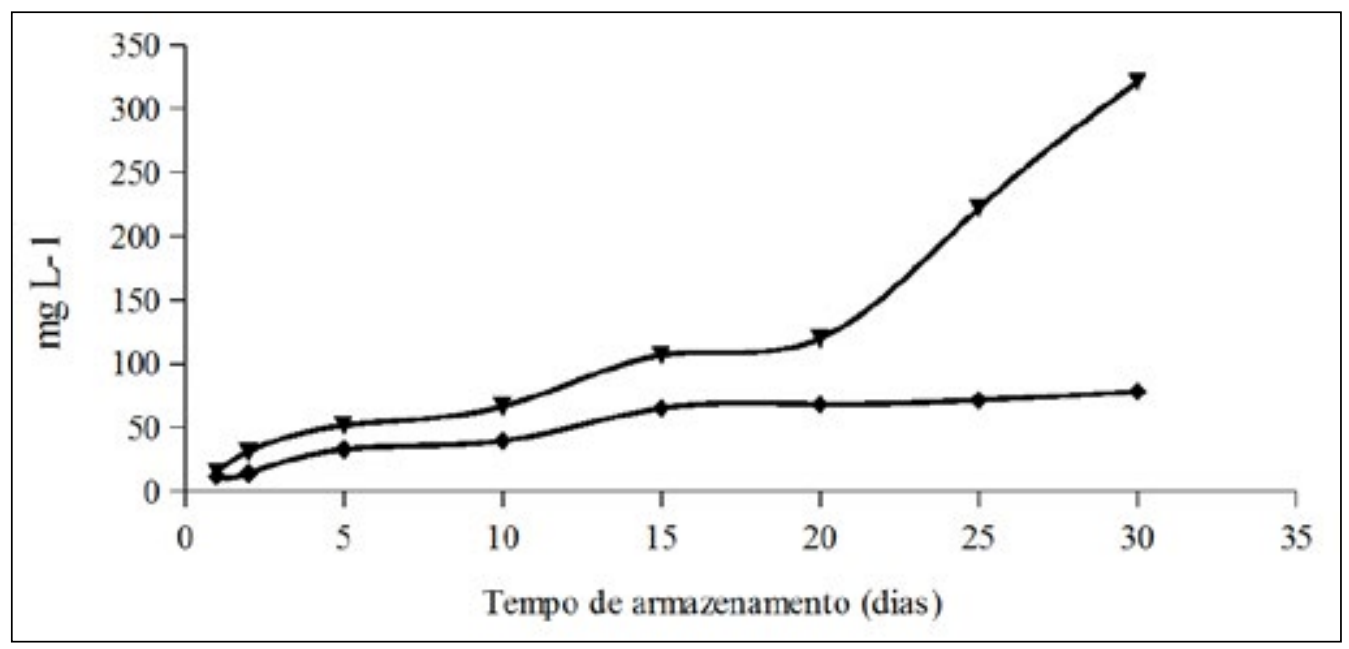

Fonte: dos autores.

Esse comportamento que, segundo Ordóñez (2005), é explicado devido à termoestabilidade das proteases e das lipases elaboradas pelas bactérias psicotróficas. Isso é percebido nos produtos já industrializados, pois continuam hidrolisando a caseína durante o período de estocagem sobre a forma semelhante à hidrolise realizada pela quimosina, em condições de temperatura e pH favoráveis aumentando o índice de CMP. A perda de qualidade, como a geleificação em leite UHT durante a estocagem e perda das características sensoriais estão relacionadas a essas enzimas.

\section{CONCLUSÃO}

Mesmo que o leite in natura, leite pasteurizado e o leite UHT recémprocessados tenham apresentado baixas concentrações de CMP, o índice deste peptídeo aumenta gradualmente ao longo do tempo de armazenamento, que foi progressivo durante todo esse período. Desse modo, não é factível a análise do índice de CMP ser atribuída como um parâmetro de controle de fraudes em leite UHT, uma vez que este composto se apresenta naturalmente no leite, podendo ter variados teores dependendo das condições de estocagem. Nem sempre uma concentração de CMP acima de $30 \mathrm{mg} \mathrm{L}^{-1}$, valor estabelecido pelo MAPA, representa que o leite foi adulterado por adição de soro de queijo, principalmente em análises durante o período de estocagem. 
Há a necessidade da continuidade do estudo, realizando o monitoramento por toda a vida de prateleira do produto, ou até mesmo um acompanhamento mais detalhado das outras alterações, como a de sabor e sedimentos ou precipitados formados pela ação das enzimas.

\section{REFERÊNCIAS}

BRASIL. Ministério da Agricultura Pecuária e Abastecimento. Regulamento Técnico de Identidade e Qualidade do Leite UAT (UHT): RDC: 146. Brasília, DF, 1996.

BRASIL. Ministério da Agricultura Pecuária e Abastecimento. Instrução Normativa $n^{\circ}$ 51. Diário Oficial da União, Brasília, DF, 20 set. 2002.

BRASIL. Ministério da Agricultura Pecuária e Abastecimento. Instrução Normativa $\mathrm{n}^{\circ}$ 68. Diário Oficial da União, Brasília, DF, 14 dez. 2006.

BRASIL. Ministério da Agricultura Pecuária e Abastecimento. Instrução Normativa n 69. Diário Oficial da União, Brasília, DF, 15 de dez. 2006.

BRASIL. Ministério da Agricultura, Pecuária e Abastecimento. Instrução Normativa $n^{\circ}$ 62. Diário Oficial da União. Brasília, DF, 29 dez. 2011.

CUNHA, M.F.; BRANDÃO, S.C.C. A coleta a granel pode aumentar os riscos com as bactérias psicrotróficas. Indústria de Laticínios. Jul/ago, 2000. 71-73.

EMBRAPA - Empresa Brasileira de Pesquisa Agropecuária. Diagnóstico da qualidade do leite, impacto para a indústria e a questão dos resíduos de antibióticos. Juiz de Fora: Embrapa Gado de Leite; Epamig/CT/ILCT, 2003. 168 p.

LORENZETTI, D.K. Influência do tempo e temperatura no desenvolvimento de microrganismos psicrotróficos no leite cru de dois estados da região sul [Dissertação]. Universidade Federal do Paraná, Curitiba, 2006. 71 p.

ORDÓÑEZ, J.A. Tecnologia de Alimentos - Alimentos de Origem Animal. v2. Porto Alegre: Artmed, 2005. 280 p.

PINTO, C.L.O; CARDOSO, R.R.; VANETTI, M.C.D. Bactérias Psicrotróficas Proteolíticas e Potencial Deteriorador a Temperaturas de Refrigeração. Revista do Instituto de Laticínios Cândido Tostes; v. 59, no 339, julho/agosto 2004, p. 110-117.

TRONCO, V.M. Manual para inspeção da qualidade do leite. $4^{\text {a }}$ ed. Porto Alegre: Ufsm, 2008. 166 p. 